\title{
GVHD Prophylaxis (Immunosuppression)
}

\author{
David Michonneau and Gérard Socié
}

\subsection{Introduction}

The most life-threatening complication of alloHSCT is the graft-versus-host disease (GVHD) which occurs when $\mathrm{T}$ cells from the recipient recognize the host as foreign. Despite 50 years of history and nearly half a million of procedures performed worldwide, GVHD remains the most challenging issue physicians are facing on a daily basis.

Overall, 30-50\% of the patients will develop acute GVHD, and around 15\% will have severe GVHD (grades III-IV). The main risk factor for developing chronic GVHD is the previous development of the acute form of the disease.

The pathophysiology, diagnosis, and management of both acute and chronic GVHD will be covered by other chapters in this Handbook (Chaps. 43 and 44). This chapter will summarize the use of IS to prevent the development of acute GVHD since attempt to prevent chronic GVHD basically rely on the ability to prevent the acute disease. Readers with interest on a more detailed overview of the acute GVHD biological process, prevention, and therapy can

D. Michonneau $\cdot$ G. Socié $(\bowtie)$

Hematology/Transplantation, AP/HP Hospital St Louis, Paris, France

University Paris VII, Denis Diderot, Paris, France

INSERM UMR 1160, Paris, France

e-mail: gerard.socie@aphp.fr refer to an excellent recent review (Zeiser and Blazar 2017).

\subsection{GVHD Prophylaxis After MAC; The "Gold" Standard; CNI in Combination with MTX}

Back in the mid-1980s, Storb and colleagues reported that the combination of CSA/MTX (Table 25.1) was superior to CSA in a series of prospective randomized phase 3 trials (Storb et al. 1986). This gold standard regimen remains the most widely used in Europe today as prophylaxis regimen especially after MAC.

In the late 1990s, another CNI-based prophylactic regimen using tacrolimus (TAC) in conjunction with MTX was developed, and two randomized phase 3 trials were published after MAC in HLA-identical and URD, respectively (Ratanatharathorn et al. 1998; Nash et al. 2000). Although both reported a significant decreased in the incidence of grade II-IV acute GVHD, none of the two could demonstrate an improved survival rate with TAC/MTX as compared to CSA/MTX. The reasons for this lack of improvement are twofold: (1) in the trial performed from HLA-identical sibling D, there was an imbalanced of disease risk among the two groups with higher risk patients with leukemia among patients receiving TAC/MTX, and (2) for the trial in URD, the HLA-typing methodology at 
Table 25.1 CSA/MTX for GVHD prophylaxis

\begin{tabular}{|l|l|l|}
\hline $\begin{array}{l}\text { Drug } \\
\text { posology }\end{array}$ & $\begin{array}{l}\text { Cyclosporine } \\
\begin{array}{l}\text { engraftment then } \\
\text { engray IV till } \\
\text { orally }\end{array}\end{array}$ & $\begin{array}{l}\text { Methotrexate } \\
15 \mathrm{mg} / \mathrm{m}^{2} \text { day }+1 \\
10 \mathrm{mg} / \mathrm{m}^{2} \text { day }+3, \\
+6,+11\end{array}$ \\
\hline $\begin{array}{l}\text { Adjusting } \\
\text { dose }\end{array}$ & $\begin{array}{l}\text { Target dose to } \\
150-200 \mathrm{ng} / \mathrm{mL} ; \\
\text { adjust to renal } \\
\text { function }\end{array}$ & $\begin{array}{l}\text { Day } 11 \text { may be } \\
\text { omitted if grade } \\
\text { III/IV mucositis }\end{array}$ \\
\hline Interaction & $\begin{array}{l}\text { Numerous; ++ with } \\
\text { azoles }\end{array}$ & Mucositis \\
\hline $\begin{array}{l}\text { Secondary } \\
\text { effects }\end{array}$ & $\begin{array}{l}\text { Numerous } \\
\text { Renal insufficiency, } \\
\text { CNS, and } \\
\text { endothelial toxicities }\end{array}$ & \\
\hline
\end{tabular}

that time was serologically based and thus included a very high proportion of patients with almost certainly high degree of mismatching. Nevertheless it should be stressed that the TAC/ MTX regimen is currently considered as the American gold standard, while it never reached popularity in Europe.

CSA and TAC inhibit GVHD by preventing the activation of the nuclear factor of activated T-cell (NFAT) family of transcription factors, thereby reducing the transcription of interleukin2 and the activation of effector $\mathrm{T}$ cells, albeit with a concurrent reduction in levels of interleukin-2dependent anti-inflammatory Tregs.

\subsection{GVHD Prophylaxis After RIC; Is CNI Plus MMF Standard?}

From the early development of the RIC, two regimens have been used in the setting of RIC, CSA (or TAC) alone or in combination with MMF (reviewed in; Zeiser and Blazar 2017). Somewhat surprisingly the association of CSA/MMF while largely used worldwide has never been tested stringently in the setting of a large randomized prospective randomized trial. CNI in this setting are usually used at the same dose (and share the same toxicity profile) as after MAC. MMF's toxicity mainly relies on sometimes unpredictable hematological toxicity. Attention must be paid to the use of ganciclovir (for $\mathrm{CMV}$ reactivation) in addition to MMF because of the risk of severe pancytopenia. MMF is usually delivered at the dose of $30 \mathrm{mg} / \mathrm{kg} /$ day split into two to three doses. Anecdotal evidence suggests depending on the transplant situation (i.e., HLA-identical vs. URD) that MMF should be delivered (till day +80 ?) in recipients from URD.

\subsection{Can PT-CY Be Considered as Standard GVHD Prophylaxis in Transplantation from Haploidentical Donors and Beyond?}

There is a recent bloom in the use of haploidentical donor during the past few years worldwide. While initial attempt was to use megadose of CD34+ selected HSC, the advent of PT-CY has really revolutionized this procedure. The PT-CY designed by Baltimore's group includes CY $50 \mathrm{mg} / \mathrm{kg}$ on day +3 and +4 followed by TAC/ MMF. Toxicities include those associated with CNI and MMF. Specific toxicity associated with CY includes hemorrhagic cystitis and the rare but potentially serious early cardiologic dysfunction. Although the incidence of acute GVHD remains significant (in around $1 / 3$ of the patients), there is now some evidence that PT-CY might be associated with low rate of chronic GVHD (reviewed in; Fuchs 2017).

Furthermore, beyond the setting of haploidentical transplant, PT-CY has gained popularity in other setting including transplantation from URD and HLA-identical sibling. Although it seems unlikely today that any formal randomized trial (vs. ATG) will be launched after haplo-HSCT, it would be of major scientific interest to prospectively compare within a phase 3 trial ATG vs. PT-CY.

Finally, whether PT-CY is equally effective after RIC and MAC regimen is currently unknown as it is unknown if other combination like sirolimus (SIR) + MMF can be as effective as (or less effective as) CNI/MMF in addition to PT-CY in the haploidentical situation or even if PT-CY can safely be used as a single agent after HLAidentical sibling transplants, as recently reported (Mielcarek et al. 2016). 
CY administered in two doses scheduled soon after transplantation depletes highly proliferating alloreactive conventional $\mathrm{T}$ cells while helping to preserve Tregs.

\subsection{ATG or Alemtuzumab for GVHD Prophylaxis in HSCT}

Since almost two decades, both ATG and alemtuzumab (ALEM) have been used to prevent GVHD especially after transplantation from URD. ALEM although efficacious in preventing acute GVHD has never been tested prospectively in a randomized phase 3 trial and has almost exclusively been developed in the UK. ATG however has been tested in four prospective randomized phase 3 trials. Three out of these four used anti-T-lymphocyte globulin (ATLG) and one rabbit ATG (rATG). However, the design, the time period, patients' selection, donor type, and primary end point of these four randomized trials differ (see Table 25.2 for references). From the perspective of GVHD prophylaxis efficacy, all four trials demonstrated a significant decrease in chronic GVHD rate and in three out of the four a statistical significant decrease in the rate of acute GVHD. Other end points varied among the four trials. In particular the American trial by Soiffer et al. was the only one in which patients who received ATLG experienced an increased rate of relapse mainly in patients with AML who received TBI as part of a MAC pre-transplant.

\subsection{New Immunosuppressive Regimens for GVHD Prophylaxis}

With current treatment strategies summarized above, the rate of moderate to severe acute GVHD remains of concern in the range of $20-50 \%$. As reviewed elsewhere in the Handbook, the treatment of acute and of chronic GVHD with high-dose steroids remains unsatisfactory with 30-50\% of the patients being steroid resistant or dependent. There is thus an unmet clinical need in GVHD prophylaxis. After years of lack of new agent in this setting, the better knowledge of basic T-cell immunology, of the pathophysiology of the disease, and new drug development by the industry, new agents have been tested mostly in phase 2 trials which appeared to be promising. This section summarized the drugs with most advanced development that reported an acute GVHD incidence in the $20 \%$ range (i.e., a range that may warrant development of subsequent phase 3 trials). Readers with interest on a more detailed portfolio of current drug development and new targets could refer to a recent review (Zeiser and Blazar 2017).

In contrast to CNI, SIR, an mTOR inhibitor, is a more potent suppressor of the expansion of conventional $\mathrm{T}$ cells than Tregs, owing to the greater dependence of conventional T cells on the mTORprotein kinase B pathway. This was the basis of the development by the Dana-Farber Cancer Institute (DFCI) group of a regimen that leads to an estimated cumulative incidence of acute GVHD grades II-IV of $20.5 \%$ and of less than $5 \%$

Table 25.2 Four randomized trials using ATG as a GVHD prophylaxis

\begin{tabular}{|c|c|c|c|c|}
\hline & Finke et al. (2009) & Kroger et al. (2016) & Soiffer et al. (2017) & Walker et al. (2016) \\
\hline $\mathrm{N}$ & 202 & 168 & 254 & 203 \\
\hline Product & ATLG & ATLG & ATLG & rATG \\
\hline $\begin{array}{l}\text { Primary end } \\
\text { point }\end{array}$ & GVHD & cGVHD & cGVHD-free survival & Freedom from all IST \\
\hline Conditioning & MAC & MAC & MAC & MAC+RIC \\
\hline Donor & URD & Id. Sibling & URD & URD \\
\hline $\begin{array}{l}\text { GvHD } \\
\text { prophylaxis }\end{array}$ & $\mathrm{CSA}+\mathrm{MTX}$ & $\mathrm{CSA}+\mathrm{MTX}$ & $\mathrm{TAC}+\mathrm{MTX}$ & $\begin{array}{l}\text { CSA or TAC }+ \text { MTX or } \\
\text { MMF }\end{array}$ \\
\hline Acute GVHD & $\begin{array}{l}33 \text { vs. } 51 \% \text { (grade } \\
\text { II-IV) }\end{array}$ & $\begin{array}{l}11 \text { vs. } 18 \% \text { (grade } \\
\text { II-IV) }\end{array}$ & $\begin{array}{l}23 \text { vs. } 40 \% \text { (grade } \\
\text { II-IV) }\end{array}$ & 50 vs. $65 \%$ (any grade) \\
\hline Chronic GVHD & Decreased & Decreased & Decreased & Decreased \\
\hline
\end{tabular}


grades III-IV. This prompted a large trial of the BMTCTN comparing TAC/SIR to TAC/ MTX. The primary end point of the trial was to compare grade II-IV acute GVHD-free survival using an intention-to-treat analysis of 304 randomized subjects. There was no difference in the probability of day 114 grade II-IV acute GVHDfree survival ( $67 \%$ vs. $62 \%, P=0.38)$. Grade IIIV GVHD was similar in the TAC/SIR and TAC/ MTX arms (26\% vs. $34 \%, P=0.48$ ) (Cutler et al. 2014). A smaller randomized single-center phase 2 study found however less cumulative incidence with $43 \%$ grade II-IV after TAC/SIR (as compared to an unexpected high rate of $89 \%$ after TAC/MTX) (Pidala et al. 2012).

Encouraging rates have also been reported by two other compounds: Bortezomib (BOR) (Koreth et al. 2012) and Maraviroc in 2012 (Reshef et al. 2012) delivered in addition to TAC/MTX. These two drugs as well as $\mathrm{CY}$ have been then tested in randomized phase 2 trials in the setting of HSCT (BMTCTN 1203 trial) after RIC in a pick-the-winner-designed trial (i.e., aimed to test in a multicenter setting the three drugs) and compared to prospective contemporary cohort of patients who received TAC/MTX. The final results of this trial closed for recruitment will be available in 2018 . Finally, in an open-label three-arm phase 2 randomized controlled trial, investigator at the DFCI compared grade II-IV acute GVHD between conventional TAC/MTX (A) vs. BOR/TAC/MTX (B) and vs. BOR/SIR/TAC (C), in RIC-HSCT recipients from URD in 138 patients. Day +180 grade II-IV acute GVHD rates were similar (A 32.6\%, B $31.1 \%$, C $21 \%$ ) as was the 2-year NRM. Overall, the BOR-based regimens evaluated did not seem to improve outcomes compared with TAC/MTX therapy (Koreth et al. 2018).

Finally, based on preclinical works in mice models, two drugs Vorinostat and Tocilizumab provided exciting results and were supported by ancillary biological data in humans.

- Vorinostat, a histone deacetylase inhibitor, at low concentration has anti-inflammatory and immunoregulatory effects. Pavan Reddy's group in Michigan provided compelling evidences that in preclinical models Vorinostat reduced GVHD rate, suppressed proinflammatory cytokines, regulated APCs, and enhanced Treg functions. In two separate trials (Choi et al. 2014, 2017), authors translated their findings in the clinical setting. In one trial where Vorinostat was added to standard prophylaxis after RIC in HLA-identical siblings, acute GVHD grade II-IV rate was $22 \%$ and that of grades III-IV of $6 \%$. In another trial after MAC in URD, the acute GVHD rates were similar.

- The addition of Tocilizumab to CNI+ MTX standard prophylaxis has been tested by two different groups (Kenedy et al. 2014; Dorobyski et al. 2018). Tocilizumab is a humanized anti-IL-6 receptor monoclonal antibody. IL-6 levels are increased early during GVHD and are present in all target tissues. Blockade of the IL-6 signaling pathway has been shown to reduce the severity of GVHD and to prolong survival in experimental models. Investigators in Milwaukee and in Brisbane conducted two separate phase 2 trials using Tocilizumab, and both found very low rate of grade II-IV acute GVHD (less than $15 \%$ ).

Other new agents are currently either tested in preclinical models or are in the early stage of development in clinical trials (reviewed in Zeiser and Blazar 2017). New strategies that have shown efficacy in preclinical models of GVHD include the inhibition of Janus kinase (JAK) and rhoassociated protein kinase 1 (ROCK-1). The blockade of phosphatidylinositol 3-kinase (PI3K), mitogen-activated protein kinase (MEK) proteins 1 and 2, aurora A kinase, and cyclindependent kinase 2 (CDK2) have been shown to reduce acute GVHD in murine models.

\subsection{Conclusion and Perspective}

Despite decades of experience with transplantation, GVHD still occurs in over $40 \%$ of the patients. When acute GVHD develops, the main treatment is high-dose steroids. However around one third of the patients will be steroid resistant. 
Steroid resistance remains associated with a dismal prognosis (30-40\% 1-year survival). These data urge for developing new strategies to prevent GVHD. Fortunately enough, based on preclinical findings and improved knowledge on the immune biology of HSCT, recent drug combination opens the gate for future development.

\section{Key Points}

- Current GVHD prophylaxis relies on $\mathrm{CNI}+$ short-term MTX after MAC and of CSA \pm MMF after RIC

- ATG has been demonstrated to decrease acute GVHD after URD transplant and of chronic GVHD

- Despite the above two points, new prophylactic regimens are clearly warranted since severe GVHD rates still lie on the $25 \%$ range

\section{References}

Choi SW, Braun T, Chang L, et al. Vorinostat plus tacrolimus and mycophenolate to prevent graft-versus-host disease after related-donor reduced intensity conditioning allogeneic haematopoietic stem-cell transplantation. Lancet Oncol. 2014;15:87-95.

Choi SW, Braun T, Henig I, et al. Vorinostat plus tacrolimus/methotrexate to prevent GVHD after myeloablative conditioning, unrelated donor HSCT. Blood. 2017;130:1760-7.

Cutler C, Logan B, Nakamura R, et al. Tacrolimus/sirolimus vs tacrolimus/methotrexate as GVHD prophylaxis after matched, related donor allogeneic HCT. Blood. 2014;124:1372-7.

Dorobyski WR, Szabo A, Zhu F, et al. Tocilizumab, tacrolimus and methotrexate for prevention of acute graft-versus-host disease: low incidence of lower gastrointestinal tract disease. Haematologica. 2018;103:717-27.

Finke J, Bethge WA, Schmoor C, et al. Standard graftversus-host disease prophylaxis with or without anti-T-cell globulin in haematopoietic cell transplantation from matched unrelated donors: a randomised, open-label, multicentre phase 3 trial. Lancet Oncol. 2009;10:855-64.

Fuchs EJ. Related haploidentical donors are better choice than matched unrelated donors: point. Blood Adv. 2017;1:397-400.

Kenedy GA, Varelias A, Vuckovic S, et al. Addition of interleukin-6 inhibition with tocilizumab to standard graft-versus-host disease prophylaxis after allogeneic stem-cell transplantation: a phase $1 / 2$ trial. Lancet Oncol. 2014;15:1451-9.

Koreth J, Kim HT, Lange PB, et al. Bortezomib-based immunosuppression after reduced-intensity conditioning hematopoietic stem cell transplantation: randomized phase II results. Haematologica. 2018;103:522-30.

Koreth J, Stevenson KE, Kim HT, et al. Bortezomibbased graft-versus-host disease prophylaxis in HLAmismatched unrelated donor transplantation. J Clin Oncol. 2012;30:3202-8.

Kroger N, Solano C, Wolschke C, et al. Antilymphocyte globulin for prevention of chronic graft-versus-host disease. N Engl J Med. 2016;374:43-53.

Mielcarek M, Furlong T, O'Donnell PV, et al. Posttransplant cyclophosphamide for prevention of graft-versus-host disease after HLA-matched mobilized blood cell transplantation. Blood. 2016;127:1502-8.

Nash RA, Antin JH, Karanes C, Fay JW, et al. Phase 3 study comparing methotrexate and tacrolimus with methotrexate and cyclosporine for prophylaxis of acute graft-versus-host disease after marrow transplantation from unrelated donors. Blood. 2000;96:2062-8.

Pidala J, Kim J, Jim H, et al. A randomized phase II study to evaluate tacrolimus in combination with sirolimus or methotrexate after allogeneic hematopoietic cell transplantation. Haematologica. 2012;97:1882-9.

Ratanatharathorn V, Nash RA, Przepiorka D, et al. Phase III study comparing methotrexate and tacrolimus (prograf, FK506) with methotrexate and cyclosporine for graft-versus-host disease prophylaxis after HLAidentical sibling bone marrow transplantation. Blood. 1998;92:2303-14.

Reshef R, Luger SM, Hexner EO, et al. Blockade of lymphocyte chemotaxis in visceral graft-versus-host disease. N Engl J Med. 2012;367:135-45.

Soiffer RJ, Kim HT, McGuirk J, et al. Prospective, randomized, double-blind, phase III clinical trial of antiT-lymphocyte globulin to assess impact on chronic graft-versus-host disease-free survival in patients undergoing HLA-matched unrelated myeloablative hematopoietic cell transplantation. J Clin Oncol. 2017;35:4003-11.

Storb R, Deeg HJ, Whitehead J, et al. Methotrexate and cyclosporine compared with cyclosporine alone for prophylaxis of acute graft versus host disease after marrow transplantation for leukemia. N Engl J Med. 1986;314:729-35.

Walker I, Panzarella T, Couban S, et al. Pre-treatment with anti-thymocyte globulin versus no anti-thymocyte globulin in patients with haematological malignancies undergoing haemopoietic cell transplantation from unrelated donors: a randomised, controlled, openlabel, phase 3, multicentre trial. Lancet Oncol. 2016;17:164-73.

Zeiser R, Blazar BR. Acute graft-versus-host disease; biologic process, prevention and therapy. N Engl J Med. 2017;377:2167-79. 
Open Access This chapter is licensed under the terms of the Creative Commons Attribution 4.0 International License (http://creativecommons.org/licenses/by/4.0/), which permits use, sharing, adaptation, distribution and reproduction in any medium or format, as long as you give appropriate credit to the original author(s) and the source, provide a link to the Creative Commons license and indicate if changes were made.

The images or other third party material in this chapter are included in the chapter's Creative Commons license, unless indicated otherwise in a credit line to the material. If material is not included in the chapter's Creative Commons license and your intended use is not permitted by statutory regulation or exceeds the permitted use, you will need to obtain permission directly from the copyright holder.

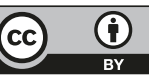

